Carlos Gervasio Rodríguez.

María Isabel Lamas

Juan de Dios Rodríguez.

Claudio Caccia

http://dx.doi.org/10.21278/brod72401

\title{
ANALYSIS OF THE PRE-INJECTION CONFIGURATION IN A MARINE ENGINE THROUGH SEVERAL MCDM TECHNIQUES
}

UDC 621.436.1:621.182.3

Original scientific paper

\begin{abstract}
Summary
The present manuscript describes a computational model employed to characterize the performance and emissions of a commercial marine diesel engine. This model analyzes several pre-injection parameters, such as starting instant, quantity, and duration. The goal is to reduce nitrogen oxides $\left(\mathrm{NO}_{\mathrm{x}}\right)$, as well as its effect on emissions and consumption. Since some of the parameters considered have opposite effects on the results, the present work proposes a MCDM (Multiple-Criteria Decision Making) methodology to determine the most adequate pre-injection configuration. An important issue in MCDM models is the data normalization process. This operation is necessary to convert the available data into a non-dimensional common scale, thus allowing ranking and rating alternatives. It is important to select a suitable normalization technique, and several methods exist in the literature. This work considers five well-known normalization procedures: linear max, linear max-min, linear sum, vector, and logarithmic normalization. As to the solution technique, the study considers three MCDM models: WSM (Weighted Sum Method), WPM (Weighted Product Method) and TOPSIS (Technique for Order Preference by Similarity to Ideal Solution). The linear max, linear sum, vector, and logarithmic normalization procedures brought the same result: $-22^{\circ}$ CA ATDC pre-injection starting instant, $25 \%$ pre-injection quantity and $1-2^{\circ} \mathrm{CA}$ pre-injection duration. Nevertheless, the linear max min normalization procedure provided a result, which is different from the others and not recommended.
\end{abstract}

Key words: marine diesel engine; CFD; emissions; consumption

\section{Introduction}

Global pollution is currently reaching an alarming rate. In the marine field, marine engines are relevant sources of particulate matter $(\mathrm{PM}), \mathrm{NO}_{\mathrm{x}}$, and other undesirable substances such as $\mathrm{SO}_{\mathrm{x}}, \mathrm{CO}_{2}, \mathrm{CO}, \mathrm{HC}$, etc. [1-6]. Among those substances, $\mathrm{NO}_{\mathrm{x}}$ and $\mathrm{SO}_{\mathrm{x}}$ are currently receiving special attention due to the increasingly strict limitations imposed by the IMO (International Maritime Organization) and other organisms [7-16]. In recent years, the need to reduce $\mathrm{NO}_{\mathrm{x}}$ emissions led to several measures. Briefly, these can be divided into primary 
measures (which focus on the engine performance) and secondary measures (which focus on removing $\mathrm{NO}_{\mathrm{x}}$ from the exhaust gases). Most of primary measures are of recent application. Among them, the present work focuses on modifying the injection system, particularly through pre-injection strategies. The main drawback of pre-injection policies (and most $\mathrm{NO}_{\mathrm{x}}$ reduction methods in general), is that $\mathrm{NO}_{\mathrm{x}}$ decreases at the expense of the increase in the emissions of other pollutants and/or overall fuel consumption. In accordance with this observation, it is crucially necessary to establish a formal procedure to select the most adequate pre-injection configuration. MCDM turns out to be a formal tool for handling decision problems involving conflicting criteria. Since its introduction in 1960, MCDM constitutes a continuously growing technique, employed in many fields. It is also referred to as MCDA (Multiple-Criteria Decision Analysis), MDDM (Multiple-Dimensions Decision Making), MODM (Multiple-Objective Decision Making), or MADM (Multiple-Attributes Decision Making).

The goal of MCDM is to find an appropriate compromise among conflicting criteria. In a nutshell, MCDM models consider different alternatives, criteria, and their corresponding weights. In most MCDM problems, criteria have different scales (e.g. consumption, emissions, mass, temperature...); for this reason, it is necessary to implement some procedures to normalize data and obtain a common non-dimensional scale. This allows the comparison of all data in order to provide a final score for each alternative. According to this, data normalization is a primary component of MCDM problems since it transforms the raw input data into numerical and comparable values. Several normalization methods have been proposed in the literature. Particularly, Jahan et al. [17] reviewed the state of the art about normalization techniques and identified. The effect of normalization procedures is still an open question and there is no consensus on an overall best method [18-19]. Consequently, the result may be different depending on the normalization technique employed [20]. As a matter of fact, several works compare different approaches [21-23]. Another important issue in MCDM models consists in the selection of the method. Several MCDM methods are available, and some authors affirm that choosing a MCDM method is a MCDM problem itself. In this regard, the so-called Pearson and Spearman correlations are useful to analyze the results deriving from different methods [24-26].

The present research aims at defining a pre-injection strategy to reduce the emission of $\mathrm{NO}_{\mathrm{x}}$ in a commercial marine engine (the Wärtsilä 6L 46) using data form a CFD model which was built to collect data concerning SFC (Specific Fuel Consumption) and emissions of $\mathrm{NO}_{\mathrm{x}}$, $\mathrm{CO}$, and $\mathrm{HC}$ using different pre-injection parameters.

The study uses data coming from 125 simulation cases carried out using different combinations of input parameters and employs MCDM techniques to define the most suitable alternative among them. It considers five normalization methods: linear max normalization, linear max-min normalization, linear sum normalization, vector normalization and logarithmic normalization. Moreover, the study compares the results of three different MCDM methods: WSM, WPM and TOPSIS.

\section{Methodology}

The first part of this section describes the engine and the corresponding CFD analysis. The second part shows the MCDM models, and the normalization techniques employed. 


\subsection{Engine characteristics and CFD model}

The marine engine Wärtsilä 6L 46 is a four-stroke diesel engine with 6 in-line cylinders. Each cylinder has 2 inlet and 2 exhaust valves. Previous works [27-33] describe the CFD model and its validation with experimental results.

The characterization of the pressure inside the cylinder of the engine employed the MALIN 6000 performance analyzer. It is a portable pressure transducer that can be connected to the bleed valve, located at the engine head. The characterization of the emissions of $\mathrm{NO}_{\mathrm{x}}$, $\mathrm{CO}, \mathrm{HC}$ and $\mathrm{CO}_{2}$ used the Gasboard-3000 series gas analyzers.

In order to characterize data at different loads, the engine operated two hours at different setups $(25 \%, 35 \%, 50 \%, 75 \%$ and $100 \%$ load). Eight tests for each load condition have been performed.

The free software OpenFOAM was used for the CFD computations. A new solver was programmed using $\mathrm{C}++$ language. The solver has the following characteristics:

- it solves the equations of conservation of mass, momentum, and energy in the domain,

- for the temporal evolution, it adopts a simple backward Euler scheme, using a constant time step corresponding to $0.1^{\circ} \mathrm{CA}$,

- the spatial discretization uses a second order scheme,

- the PISO algorithm implements the pressure-velocity coupling,

- the employed turbulence model is $\mathrm{k}-\varepsilon$,

- the fuel heat-up and evaporation is computed by the Dukowicz model [34],

- the fuel droplet and breakup is computed by the Kelvin-Helmoltz and Rayleigh-Taylor model [35],

- the combustion, $\mathrm{NO}_{\mathrm{x}}$ formation, and $\mathrm{NO}_{\mathrm{x}}$ reduction are modeled through the schemes developed by Ra and Reitz [36], Yang et al. [37], and Miller and Glarborg [38], respectively.

Figure 1 shows the mesh employed for the computational simulations. Fig. 1(a) represents the 3D mesh at TDC (top dead center) position, while Figs. 1(b) and 1(c) a cross section at BDC (bottom dead center) and TDC positions, respectively. The alternative cylinder movement was imposed to the mesh, as well as the opening-closing movement of the valves. This mesh is composed by 50125 elements at TDC and 802527 at BDC, and it is composed by hexahedrons and tetrahedrons.

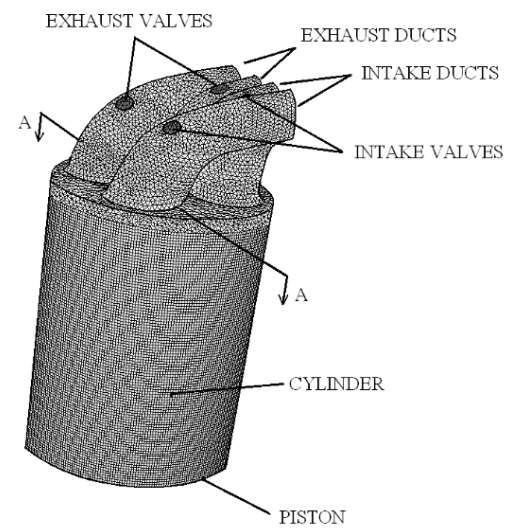

(a)

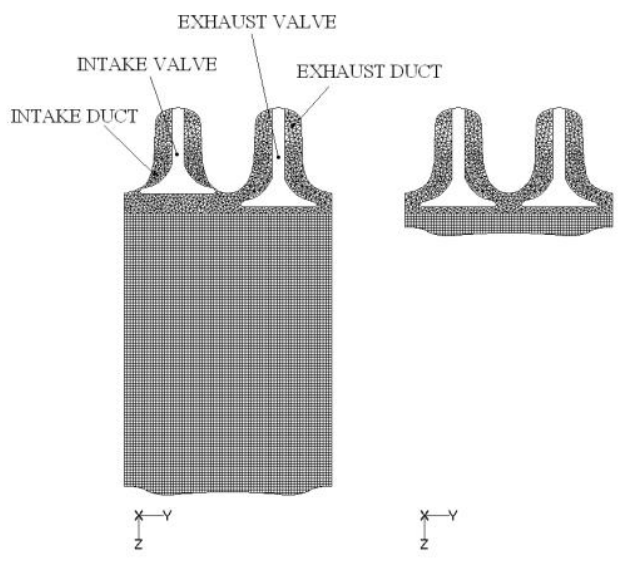

(b) (c)

Figure 1. (a) 3D mesh at BDC; (b) AA section at BDC; (c) AA section at TDC. 
Several mesh sizes have been considered in order to analyze their effects on the results. Table 1 summarizes the results obtained from three meshes of different sizes. The table shows the number of elements of these meshes at BDC and the error between experimental and numerical results regarding pressure and emissions of $\mathrm{NO}_{x}, \mathrm{CO}, \mathrm{HC}$ and $\mathrm{CO}_{2}$. Since the results obtained with the meshes 2 and 3 were similar, the mesh 2 was selected for the computations carried out on the present work.

Table 1 Mesh independence test results.

\begin{tabular}{|c|c|c|c|}
\hline Mesh & $\mathbf{1}$ & $\mathbf{2}$ & $\mathbf{3}$ \\
\hline Number of elements & 501,769 & 802,527 & $1,264,873$ \\
\hline Pressure error (\%) & 4.2 & 4.1 & 4.1 \\
\hline $\mathrm{NO}_{\mathrm{x}}$ error (\%) & 5.1 & 4.9 & 4.9 \\
\hline $\mathrm{CO}$ error (\%) & 8.1 & 7.9 & 7.9 \\
\hline $\mathrm{HC}$ error (\%) & 6.5 & 6.4 & 6.4 \\
\hline $\mathrm{CO}_{2}$ error $(\%)$ & 4.7 & 4.6 & 4.6 \\
\hline
\end{tabular}

Figs. 2 and 3 show the correspondence between experimental and numerical results . These figures illustrate the emissions, consumption and pressure obtained both numerically and experimentally. As it can be seen, the CFD model shows a good agreement in SFC, HC, CO, and $\mathrm{CO}_{2}$ with respect to experimental results. Regarding $\mathrm{NO}_{\mathrm{x}}$ emissions, the values obtained numerically are higher than the experimental ones for all engine loads. The main reason is that compression ignition engines, as opposed to spark ignition engines, operate under lean conditions. Most $\mathrm{NO}_{\mathrm{x}}$ formation kinetic models are based on $\mathrm{NO}$ thermal mechanism, which becomes significant at high temperatures, and for that reason they are not able to properly model locally lean, low-temperature regions which are typical in compression ignition engines and less common in spark ignition engines [39, 40]. Nevertheless, the numerical model predicts the $\mathrm{NO}_{\mathrm{x}}$ trend with an average error of $4.9 \%$, and it is thus considered appropriate for the present work.

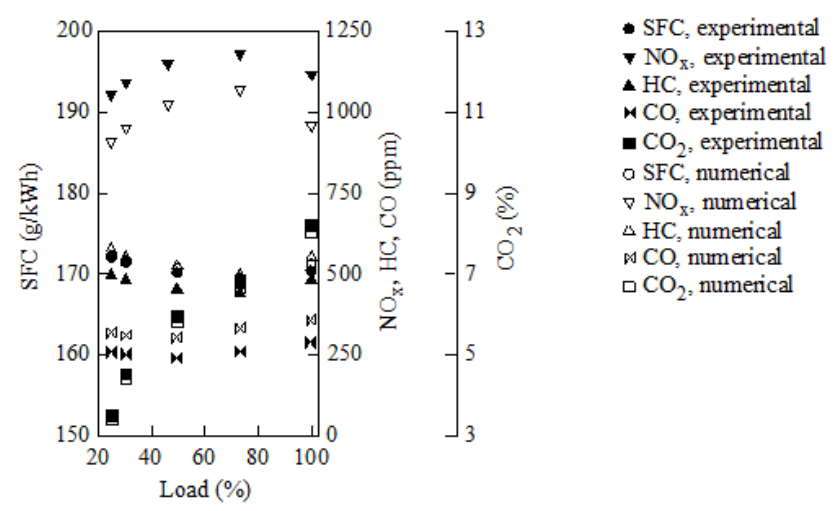

Fig. 2 Emissions and consumption at 20 to $100 \%$ load. 


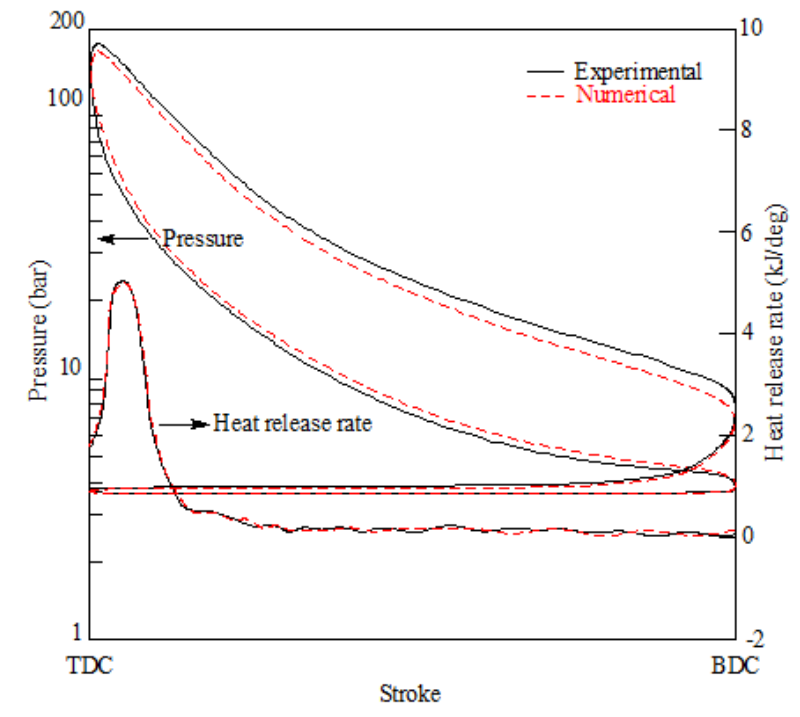

Fig. 3 In-cylinder pressure at $100 \%$ load.

\subsection{MCDM analysis}

The CFD model described in the previous section was employed to generate the data necessary to carry out the MCDM approach. 125 cases were analyzed, and they are schematically illustrated in Fig. 4. As can be seen, five pre-injection quantities (Q) were employed: $5 \%, 10 \%, 15 \%, 20 \%$, and 25\%; five pre-injection durations (D): $1^{\circ} \mathrm{CA}$ (Crank Angle), $2^{\circ} \mathrm{CA}, 3^{\circ} \mathrm{CA}, 4^{\circ} \mathrm{CA}$, and $5^{\circ} \mathrm{CA}$; and five pre-injection starting instants (S): $-22^{\circ} \mathrm{CA}$ ATDC (Crank Angle After Top Dead Center), $-21^{\circ}$ CA ATDC, $-20^{\circ}$ CA ATDC, $-19^{\circ}$ CA ATDC, and $-18^{\circ} \mathrm{CA}$ ATDC. These data ranges were chosen in order to define an appropriate engine performance. Pre-injection quantities higher than $25 \%$ and pre-injection starting instants before $-22^{\circ}$ are not recommended [32].

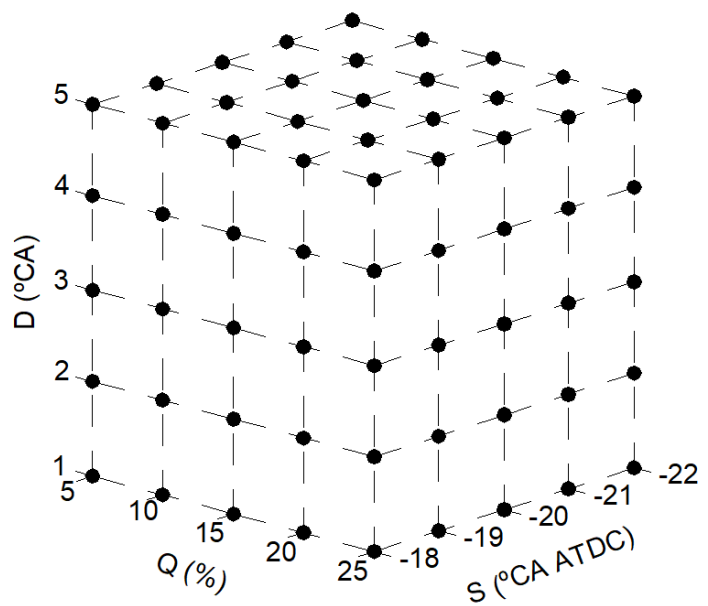

Fig. 4 Cases analyzed.

Taking into account the 125 simulations performed, and the four criteria considered: SFC, $\mathrm{NO}_{\mathrm{x}}, \mathrm{CO}$, and $\mathrm{HC}$, a $m \times n$ data matrix can be constituted with $m=125$ rows and $\mathrm{n}=4$ columns, as shown in Eq. (1). This matrix is highlighted in red color in Table 2. To simplify, this table 
only exhibits the first, second and last alternative (row). The case number and corresponding pre-injection starting angle, quantity and duration are also shown in this table.

$$
D M=\left(\begin{array}{ccc}
X_{11} & \cdots & X_{1 n} \\
\vdots & \ddots & \vdots \\
X_{m 1} & \cdots & X_{m n}
\end{array}\right)
$$

Table 2 Decision matrix.

\begin{tabular}{|c|c|c|c|c|c|c|c|}
\hline \multirow{3}{*}{$\begin{array}{l}\text { Alternative } \\
\text { (i) }\end{array}$} & \multirow{3}{*}{$\begin{array}{c}\mathbf{S} \\
\left({ }^{\circ} \mathrm{CA}\right. \\
\text { ATDC) }\end{array}$} & \multirow{3}{*}{$\begin{array}{c}\text { Q } \\
(\%)\end{array}$} & \multirow{3}{*}{$\begin{array}{c}\text { D } \\
\left({ }^{\circ} \mathrm{CA}\right)\end{array}$} & \multicolumn{4}{|c|}{ Criterion $(j)$} \\
\hline & & & & $j=1$ & $j=2$ & $j=3$ & $j=4$ \\
\hline & & & & $\begin{array}{c}\mathbf{S F C} \\
(\mathbf{g} / \mathbf{k W h})\end{array}$ & $\begin{array}{c}\mathbf{N O}_{\mathbf{x}} \\
(\mathbf{g} / \mathbf{k W h})\end{array}$ & $\begin{array}{c}\mathbf{C O} \\
(\mathrm{g} / \mathbf{k W h})\end{array}$ & $\begin{array}{c}\mathbf{H C} \\
(\mathrm{g} / \mathrm{kWh})\end{array}$ \\
\hline 1 & -22 & 5 & 1 & 190.9 & 7.38 & 4.65 & 5.72 \\
\hline \multirow[t]{3}{*}{2} & -22 & 5 & 2 & 189.0 & 7.83 & 4.67 & 5.73 \\
\hline & & & & & & & \\
\hline & & & & . & . & & \\
\hline \multirow[t]{2}{*}{. } & . & . & . & . & . & . & . \\
\hline & . & & . & . & 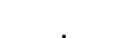 & & \\
\hline \multirow[t]{2}{*}{125} & -18 & 25 & 5 & 174.5 & 10.86 & 4.88 & 5.92 \\
\hline & \multicolumn{3}{|c|}{ Minimum value } & 173.4 & 3.70 & 4.57 & 5.60 \\
\hline \multicolumn{4}{|c|}{ Maximum value } & 206.3 & 11.79 & 5.02 & 6.12 \\
\hline
\end{tabular}

An important aspect in MCDM methods is the definition of the weight of each criterion. This refers to the degree of importance of each criterion. Instead of objective methods, subjective ones are recommended to establish the criteria weights, since experts in the field can directly define them. Objective weighting criteria methods are only recommended when there is no agreement between the experts or when the objectivity is extremely important $[27,41]$. According to this, this study considers two main requirements: consumption and emissions. Equal importance has been assigned to consumption and emissions, i.e., $50 \%$ each. Regarding emissions, the importance of $\mathrm{NO}_{\mathrm{x}}, \mathrm{CO}$ and $\mathrm{HC}$ was also distributed equally, i.e., $33.3 \%$ for each one. To summarize, Table 3 shows these values in per-unit basis. Logically, each column in Table 3 sums to 1 for the requirements. Regarding sub-requirements, the value of the part of the column corresponding to SFC is 1 and the part of the column corresponding to emissions sums to 1 . The weight of each criterion is obtained by multiplying the weight of the requirement by the weight of the sub-requirement, leading to $0.5,0.167,0.167$, and 0.167 for $\mathrm{SFC}, \mathrm{NO}_{\mathrm{x}}$, $\mathrm{CO}$, and $\mathrm{HC}$, respectively. These weights also sum to 1 .

Table 3 Criteria weights, per unit basis.

\begin{tabular}{|c|c|}
\hline Requirement $(\boldsymbol{\alpha})$ & Sub-requirement $(\boldsymbol{\beta})$ \\
\hline $\mathrm{SFC}(0.5)$ & $\mathrm{SFC}(1)$ \\
\hline & $\mathrm{NO}_{\mathrm{x}}(0.333)$ \\
Emissions $(0.5)$ & $\mathrm{CO}(0.333)$ \\
& $\mathrm{HC}(0.333)$ \\
\hline
\end{tabular}

Another important step consists on normalizing the decision matrix. The normalization process eliminates the units of each criterion to work in dimensionless form. Normalization 
converts the different measurable values into comparable similar ones, and the normalized decision matrix is a $m \times n$ matrix given by Eq. (2), whereby each $V_{i j}$ element is the normalized value of $X_{i j}$. As mentioned above, many normalization techniques are available in the literature. The most employed ones, which will be compared in the present work, are listed in Table 4. This table shows the expressions used to normalize each term of the decision matrix, both for beneficial and non-beneficial criteria. Beneficial and non-beneficial terms refer to criteria for which a higher greater value is preferable or not, respectively. In the present work, all considered criteria are non-beneficial since the goal is to reduce $\mathrm{SFC}, \mathrm{NO}_{\mathrm{x}}, \mathrm{CO}$, and $\mathrm{HC}$ as much as possible. Table 4 shows the normalization criteria used in this study: $X_{j, \min }$ and $X_{j, \max }$ are the minimum and maximum grades of the alternatives for each criterion $\mathrm{j}$.

$$
N D M=\left(\begin{array}{ccc}
V_{11} & \cdots & V_{1 n} \\
\vdots & \ddots & \vdots \\
V_{m 1} & \cdots & V_{m n}
\end{array}\right)
$$

Table 4 Normalization methods employed in the present work.

\begin{tabular}{|c|c|c|}
\hline Normalization technique & Criteria & Expression \\
\hline Linear max normalization & $\begin{array}{l}\text { Beneficial } \\
\text { Non-beneficial }\end{array}$ & $\begin{array}{l}V_{i j}=\frac{X_{i j}}{X_{j, \max }} \\
V_{i j}=1-\frac{X_{i j}}{X_{j, \max }}\end{array}$ \\
\hline Linear max-min normalization & $\begin{array}{l}\text { Beneficial } \\
\text { Non-beneficial }\end{array}$ & $\begin{aligned} V_{i j} & =\frac{X_{i j}-X_{j, \text { min }}}{X_{j, \text { max }}-X_{j, \text { min }}} \\
V_{i j} & =\frac{X_{j, \text { max }}-X_{i j}}{X_{j, \text { max }}-X_{j, \text { min }}}\end{aligned}$ \\
\hline Linear sum normalization & $\begin{array}{l}\text { Beneficial } \\
\text { Non-beneficial }\end{array}$ & $\begin{aligned} V_{i j} & =\frac{X_{i j}}{\sum_{i=1}^{m} X_{i j}} \\
V_{i j} & =\frac{1 / X_{i j}}{\sum_{i=1}^{m}\left(1 / X_{i j}\right)}\end{aligned}$ \\
\hline Vector normalization & $\begin{array}{l}\text { Beneficial } \\
\text { Non-beneficial }\end{array}$ & $\begin{array}{c}V_{i j}=\frac{X_{i j}}{\sqrt{\sum_{i=1}^{m} X_{i j}^{2}}} \\
V_{i j}=1-\frac{X_{i j}}{\sqrt{\sum_{i=1}^{m} X_{i j}^{2}}}\end{array}$ \\
\hline Logarithmic normalization & $\begin{array}{l}\text { Beneficial } \\
\text { Non-beneficial }\end{array}$ & $\begin{aligned} V_{i j} & =\frac{\ln \left(X_{i j}\right)}{\ln \left(\prod_{i=1}^{m} X_{i j}\right)} \\
V_{i j} & =\frac{1-\frac{\ln \left(X_{i j}\right)}{\ln \left(\prod_{i=1}^{m} X_{i j}\right)}}{m-1}\end{aligned}$ \\
\hline
\end{tabular}

Once the decision matrix is normalized, the adequacy index corresponding to each $i$-th alternative, $A I_{i}$, was computed through the three procedures described below. 


\subsubsection{WSM procedure}

This procedure is also knowns as SAW (Simple Additive Weighting) or WLC (Weighted Linear Combination). This method, proposed by Churchman and Ackoff in 1954 [42], is the oldest and most widely used MCDM approach. The adequacy index is given by Eq. (3), and after applying the normalization procedures described, the most appropriate alternative is the one corresponding to the maximum $A I$.

$$
A I_{i}=\sum_{j=1}^{n} w_{j} V_{i j}
$$

whereby $w_{j}$ the weight of the $j$-th criterion.

\subsubsection{WPM procedure}

This procedure is also known as MEW (Multiplicative Exponential Weighting). This method is quite similar to WSM, and computes the adequacy index as [43]:

$$
A I_{i}=\prod_{j=1}^{n}\left(V_{i j}\right)^{w_{j}}
$$

\subsubsection{TOPSIS procedure}

The TOPSIS method, introduced by Hwang and Yoon [44], determines the so called positive ideal solution and the negative ideal solution. By computing the Euclidean distance to these two alternatives, this method provides the solution that is closest to the best one and farthest to the worst one. The main steps of the TOPSIS procedure are the following ones:

Step 1: Determining the normalized decision matrix. Although the classical TOPSIS uses the vector normalization technique, the normalization techniques described above have been compared.

Step 2: Weighting the data, given by the following expression:

$$
R_{i j}=w_{j} V_{i j}
$$

Step 3: Determining the positive ideal solution and negative ideal solution:

$$
S^{+}=\left(R_{1 j}^{+}, R_{2 j}^{+}, \ldots, R_{m j}^{+}\right)
$$

where $R_{i j}^{+}=\left[\max \left(R_{i j}\right)\right.$ if $\mathrm{j} \in \mathrm{J}^{+} ; \min \left(R_{i j}\right)$ if $\left.\mathrm{j} \in \mathrm{J}^{-}\right]$

$$
S^{-}=\left(R_{1 j}^{-}, R_{2 j}^{-}, \ldots, R_{m j}^{-}\right)
$$

where $R_{i j}^{-}=\left[\min \left(R_{i j}\right)\right.$ if $\mathrm{j} \in \mathrm{J}^{+} ; \max \left(R_{i j}\right)$ if $\left.\mathrm{j} \in \mathrm{J}^{-}\right]$

Step 4: Calculating the Euclidean distance of each alternative. Eqs (8) and (9) give the distance from the positive ideal solution and negative ideal solution., respectively:

$$
\begin{aligned}
& D_{i}^{+}=\sqrt{\sum_{j=1}^{n}\left(R_{i j}^{+}-S^{+}\right)^{2}} \\
& D_{i}^{-}=\sqrt{\sum_{j=1}^{n}\left(R_{i j}^{-}-S^{-}\right)^{2}}
\end{aligned}
$$

Step 5: Calculating the relative closeness to the ideal solution:

$$
C_{i}=\frac{D_{i}^{+}}{D_{i}^{-}+D_{i}^{+}}
$$

Step 6: Ranking the alternatives according to the highest $C_{i}$. A value of $C_{i}=1$ is the ideal solution and $C_{i}=0$ is the worst solution. 


\section{Results and discussion}

Tables 5 to 9 show the normalized matrixes using each of the described methods (i.e.: linear max, linear max-min, linear sum, vector and logarithmic normalization techniques, respectively). The expressions presented in Table 4 produce the normalized values. Since all criteria are non-beneficial, the expressions corresponding to non-beneficial criteria are considered. The minimum and maximum normalized values corresponding to each criterion are also shown at the end of each of the Tables 5-9. As can be seen, the linear max normalization technique provides normalized values between 0 (minimum value) and a number lower than 1 (maximum value). The linear max-min normalization provides a normalized matrix with data within the range [0 1], where 0 is the worst value and 1 the best one. The linear sum and logarithmic normalization techniques provide normalized values considerably smaller than the other ones, and finally the vector normalization technique provides normalized values close to 1 .

Table 5 Normalized matrix using the linear max normalization technique.

\begin{tabular}{|c|c|c|c|c|c|c|c|}
\hline \multirow{2}{*}{$\begin{array}{l}\text { Alternative } \\
\text { (i) }\end{array}$} & \multirow{2}{*}{$\begin{array}{c}\text { S } \\
\text { ("CA ATDC) }\end{array}$} & \multirow{2}{*}{$\begin{array}{c}\mathrm{Q} \\
(\%)\end{array}$} & \multirow{2}{*}{$\begin{array}{c}\text { D } \\
\left({ }^{\circ} \mathrm{CA}\right)\end{array}$} & \multicolumn{4}{|c|}{ Criterion (j) } \\
\hline & & & & $j=1, \mathrm{SFC}$ & $j=2, \mathrm{NO}_{\mathrm{x}}$ & $j=3, \mathrm{CO}$ & $j=4, \mathrm{HC}$ \\
\hline 1 & -22 & 5 & 1 & 0.074593 & 0.374650 & 0.072703 & 0.066747 \\
\hline 2 & -22 & 5 & 2 & 0.083981 & 0.335886 & 0.068517 & 0.063859 \\
\hline & . & . & . & & & . & \\
\hline & - & $\cdot$ & . & & & & \\
\hline & . & . & . & & & . & . \\
\hline 125 & -18 & 25 & 5 & 0.154040 & 0.079254 & 0.027977 & 0.033914 \\
\hline & & & & & & & \\
\hline \multicolumn{4}{|c|}{ Minimum value } & 0 & 0 & 0 & 0 \\
\hline \multicolumn{4}{|c|}{ Maximum value } & 0.159514 & 0.686433 & 0.088126 & 0.085443 \\
\hline
\end{tabular}

Table 6 Normalized matrix using the linear max min normalization technique.

\begin{tabular}{|c|c|c|c|c|c|c|c|}
\hline \multirow{2}{*}{$\begin{array}{l}\text { Alternative } \\
\quad(i)\end{array}$} & \multirow{2}{*}{$\begin{array}{c}\mathrm{S} \\
\left({ }^{\circ} \mathrm{CA} A T D C\right)\end{array}$} & \multirow{2}{*}{$\begin{array}{l}\mathrm{Q} \\
(\%)\end{array}$} & \multirow{2}{*}{$\begin{array}{c}\mathrm{D} \\
\left({ }^{\circ} \mathrm{CA}\right)\end{array}$} & \multicolumn{4}{|c|}{ Criterion $(j)$} \\
\hline & & & & $j=1, \mathrm{SFC}$ & $j=2, \mathrm{NO}_{\mathrm{x}}$ & $j=3, \mathrm{CO}$ & $j=4, \mathrm{HC}$ \\
\hline 1 & -22 & 5 & 1 & 0.467628 & 0.545793 & 0.824986 & 0.781182 \\
\hline 2 & -22 & 5 & 2 & 0.526481 & 0.489321 & 0.777482 & 0.747387 \\
\hline & & & & & & & \\
\hline . & & & & . & & . & \\
\hline . & & & . & . & . & . & . \\
\hline . & & & . & . & . & . & . \\
\hline & & & & & & & \\
\hline 125 & -18 & 25 & 5 & 0.995682 & 0.115157 & 0.317462 & 0.336920 \\
\hline \multicolumn{4}{|c|}{ Minimum value } & 0 & 0 & 0 & 0 \\
\hline \multicolumn{4}{|c|}{ Maximum value } & 1 & 1 & 1 & 1 \\
\hline
\end{tabular}


C.G. Rodriguez, M.I. Lamas,

J.D. Rodriguez, C. Caccia
Analysis of the pre-injection configuration in a marine engine through several MCDM techniques

Table 7 Normalized matrix using the linear sum normalization technique.

\begin{tabular}{|c|c|c|c|c|c|c|c|}
\hline \multirow{2}{*}{$\begin{array}{c}\text { Alternative } \\
\quad(i)\end{array}$} & \multirow{2}{*}{\begin{tabular}{|c|c}
$\mathrm{S}$ \\
$\left({ }^{\circ} \mathrm{CA}\right.$ ATDC) \\
\end{tabular}} & \multirow{2}{*}{$\begin{array}{c}\mathbf{Q} \\
(\%)\end{array}$} & \multirow{2}{*}{$\begin{array}{c}\mathrm{D} \\
\left({ }^{\circ} \mathrm{CA}\right)\end{array}$} & \multicolumn{4}{|c|}{ Criterion $(j)$} \\
\hline & & & & $j=1, \mathrm{SFC}$ & $j=2, \mathrm{NO}_{\mathrm{x}}$ & $j=3, \mathrm{CO}$ & $j=4, \mathrm{HC}$ \\
\hline 1 & -22 & 5 & 1 & 0.007682 & 0.009063 & 0.008159 & 0.008122 \\
\hline 2 & -22 & 5 & 2 & 0.007761 & 0.008534 & 0.008122 & 0.008097 \\
\hline . & & & & & . & & \\
\hline . & & & & & & & \\
\hline . & & & & & & & \\
\hline & & & & & & & \\
\hline 125 & -18 & 25 & 5 & 0.008404 & 0.006156 & 0.007783 & 0.007846 \\
\hline \multicolumn{4}{|c|}{ Minimum value } & 0.007109 & 0.005668 & 0.007566 & 0.007580 \\
\hline \multicolumn{4}{|c|}{ Maximum value } & 0.008459 & 0.018075 & 0.008297 & 0.008288 \\
\hline
\end{tabular}

Table 8 Normalized matrix using the vector normalization technique.

\begin{tabular}{|c|c|c|c|c|c|c|c|}
\hline \multirow{2}{*}{$\begin{array}{c}\text { Alternative } \\
\text { (i) }\end{array}$} & \multirow{2}{*}{$\begin{array}{c}\mathrm{S} \\
\left({ }^{\circ} \mathrm{CA} \text { ATDC) }\right. \\
\end{array}$} & \multirow{2}{*}{$\begin{array}{c}Q \\
(\%)\end{array}$} & \multirow{2}{*}{$\begin{array}{c}\text { D } \\
\left({ }^{\circ} \mathrm{CA}\right) \\
\end{array}$} & \multicolumn{4}{|c|}{ Criterion (j) } \\
\hline & & & & $j=1, \mathrm{SFC}$ & $j=2, \mathrm{NO}_{\mathrm{x}}$ & $j=3, \mathrm{CO}$ & $j=4, \mathrm{HC}$ \\
\hline 1 & -22 & 5 & 1 & 0.907106 & 0.926984 & 0.912349 & 0.911944 \\
\hline \multirow[t]{3}{*}{2} & -22 & 5 & 2 & 0.908048 & 0.922458 & 0.911953 & 0.911671 \\
\hline & . & . & . & &. & & \\
\hline & . & . & . & & & & \\
\hline & . & . & . & & & & \\
\hline & & & & & & & \\
\hline 125 & -18 & 25 & 5 & 0.915081 & 0.892494 & 0.908121 & 0.908846 \\
\hline \multicolumn{4}{|c|}{ Minimum value } & 0.899618 & 0.883240 & 0.905476 & 0.905646 \\
\hline \multicolumn{4}{|c|}{ Maximum value } & 0.915630 & 0.963388 & 0.913806 & 0.913708 \\
\hline
\end{tabular}

Table 9 Normalized matrix using the logarithmic normalization technique.

\begin{tabular}{|c|c|c|c|c|c|c|c|}
\hline \multirow{2}{*}{$\begin{array}{l}\text { Alternative } \\
\quad \text { (i) }\end{array}$} & \multirow{2}{*}{$\begin{array}{c}\mathrm{S} \\
\left({ }^{\circ} \mathrm{CA} \text { ATDC }\right)\end{array}$} & \multirow{2}{*}{$\begin{array}{l}\mathrm{Q} \\
(\%)\end{array}$} & \multirow{2}{*}{$\begin{array}{c}\text { D } \\
\left({ }^{\circ} \mathrm{CA}\right)\end{array}$} & \multicolumn{4}{|c|}{ Criterion $(j)$} \\
\hline & & & & $j=1, \mathrm{SFC}$ & $j=2, \mathrm{NO}_{\mathrm{x}}$ & $j=3, \mathrm{CO}$ & $j=4, \mathrm{HC}$ \\
\hline 1 & -22 & 5 & 1 & 0.007859 & 0.007895 & 0.007841 & 0.007865 \\
\hline 2 & -22 & 5 & 2 & 0.007860 & 0.007890 & 0.007840 & 0.007865 \\
\hline 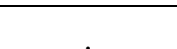 & & . & . & & . & & . \\
\hline . & & - & . & & & & \\
\hline . & & & & & & & \\
\hline & & & & & & & \\
\hline 125 & -18 & 25 & 5 & 0.007863 & 0.007862 & 0.007834 & 0.007861 \\
\hline \multicolumn{4}{|c|}{ Minimum value } & 0.007856 & 0.007855 & 0.007830 & 0.007857 \\
\hline \multicolumn{4}{|c|}{ Maximum value } & 0.007863 & 0.007954 & 0.007843 & 0.007868 \\
\hline
\end{tabular}


The results show a strong dependency on the range of the normalized data. According to the expressions shown in Table 4 for the linear max-min method, the initial data are transformed into normalized values within the range [0 1]. Nevertheless, the other methods lead to a much narrower range of the normalized data. The variation of $\mathrm{HC}$ and $\mathrm{CO}$ emissions with the preinjection starting instant and quantity is considerably small, as shown in Figs. 5 and 6, respectively. These figures represent the $\mathrm{HC}$ and $\mathrm{CO}$ emission against the pre-injection quantity and starting rate using $1^{\circ}$ pre-injection duration. Other pre-injection durations provide similar results and thus are not presented here. As can be seen in Figs. 5 and 6, the variation of $\mathrm{HC}$ and $\mathrm{CO}$ is too small, and all normalization methods reflect this fact by providing close values in the normalized matrix, except for the linear max-min normalization. Since this method transforms the values corresponding to each criterion within the range [0 1], the importance of these small variations in $\mathrm{CO}$ and $\mathrm{HC}$ emissions is incremented, i.e., small differences are always transformed to the range [0 1] independently of the initial data range, and thus small differences are extended. Nevertheless, the other normalization methods maintain the irrelevance of $\mathrm{CO}$ and $\mathrm{HC}$ during the normalization process and pay more attention to the variation of $\mathrm{NO}_{\mathrm{x}}$ emissions and consumption with the pre-injection starting instant and quantity. The variation of $\mathrm{NO}_{\mathrm{x}}$ and consumption with the pre-injection rate and starting angle is shown in Figs. 7 and 8 , respectively. These figures underline an important dependence of $\mathrm{NO}_{\mathrm{x}}$ and consumption on the pre-injection rate and starting angle.

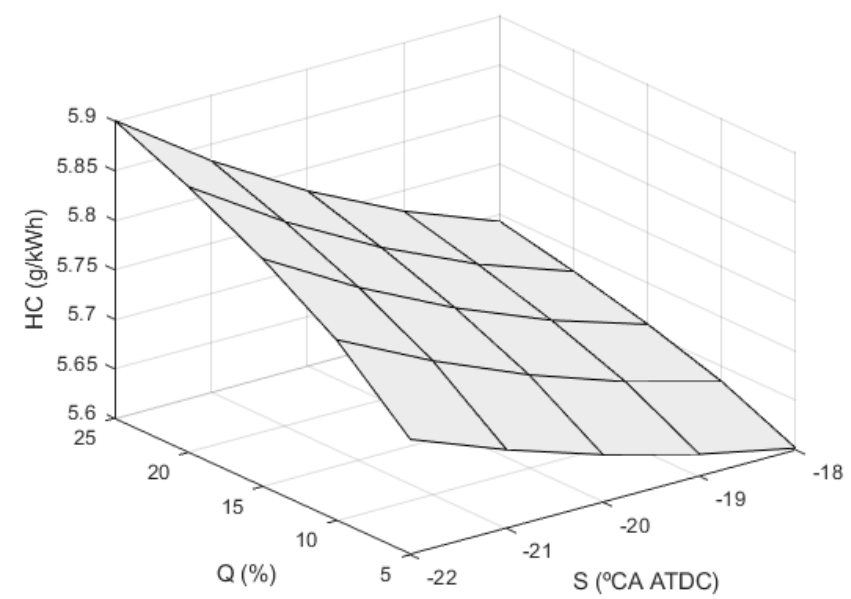

Fig. $5 \mathrm{HC}$ emissions against the pre-injection quantity and starting instant. Pre-injection duration $1^{\circ} \mathrm{CA}$.

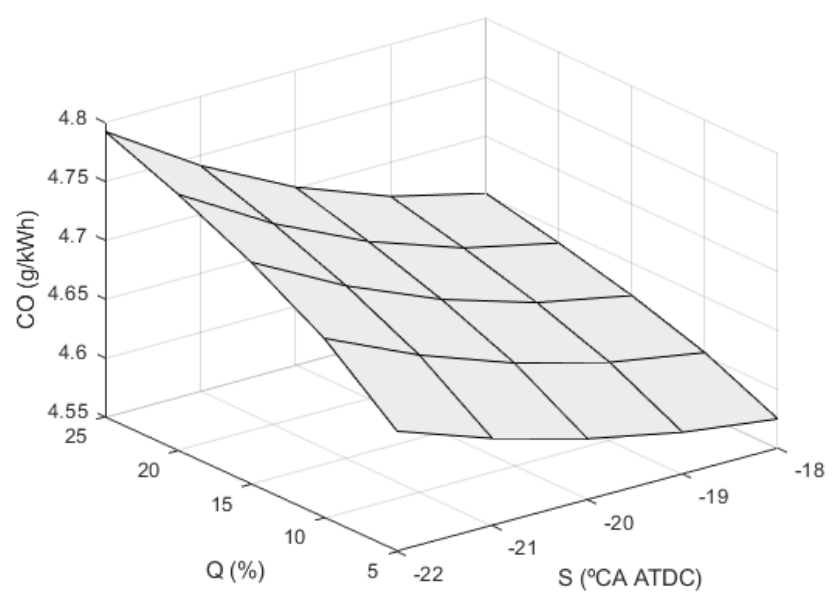

Fig. $6 \mathrm{CO}$ emissions against the pre-injection quantity and starting instant. Pre-injection duration $1^{\circ} \mathrm{CA}$. 
C.G. Rodriguez, M.I. Lamas,

J.D. Rodriguez, C. Caccia
Analysis of the pre-injection configuration in a marine engine through several MCDM techniques

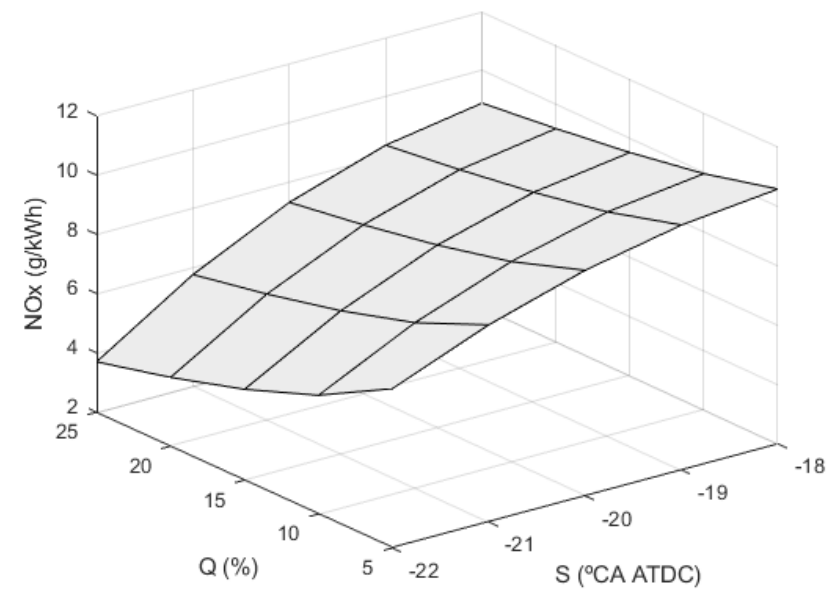

Fig. $7 \mathrm{NO}_{\mathrm{x}}$ emissions against the pre-injection quantity and starting instant. Pre-injection duration $1^{\circ} \mathrm{CA}$.

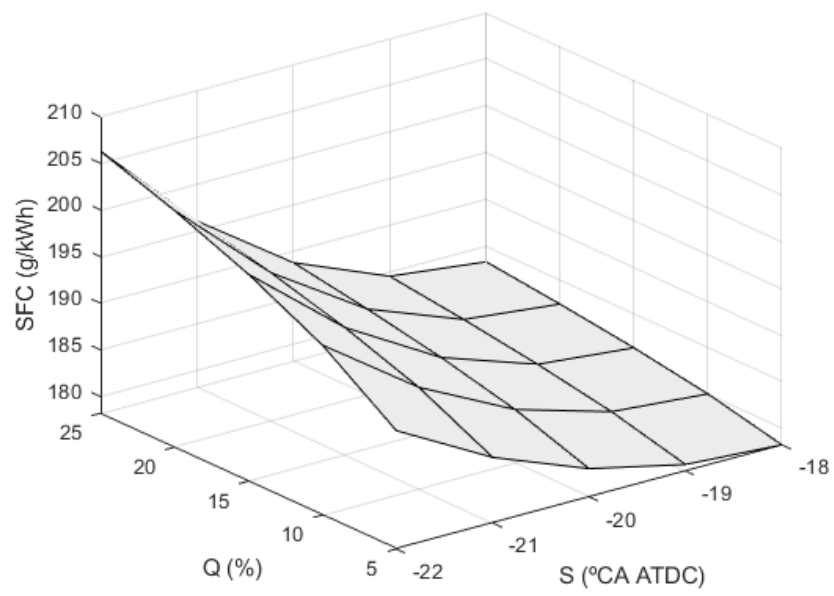

Fig. 8 Consumption against the pre-injection quantity and starting instant. Pre-injection duration $1^{\circ} \mathrm{CA}$.

Table 10 shows the highest adequacy index using the different normalizations methods analyzed in the present work. As can be seen, the linear max, linear sum, vector and logarithmic normalization methods provide practically the same result, which corresponds to $-22^{\circ}$ preinjection starting instant, $25 \%$ pre-injection quantity and $1^{\circ}$ (WSM and WPM) or $2^{\circ}$ (TOPSIS) pre-injection duration. Nevertheless, the linear max-min normalization method provides the alternative corresponding to $-18^{\circ}$ pre-injection starting instant, $5 \%$ pre-injection quantity, and $2^{\circ}$ pre-injection duration.

Table 10 Most appropriate pre-injection pattern using different normalization methods.

\begin{tabular}{|c|c|c|c|}
\hline Normalization method & $\mathbf{S ~ ( { } ^ { \mathbf { 0 } } \mathbf { C A } \text { ATDC) }}$ & $\mathbf{Q}(\boldsymbol{\%})$ & $\mathbf{D}(\boldsymbol{\%})$ \\
\hline Linear max & -22 & 25 & $1-2$ \\
\hline Linear max-min & -18 & 5 & 2 \\
\hline Linear sum & -22 & 25 & $1-2$ \\
\hline Vector & -22 & 25 & $1-2$ \\
\hline Logarithmic & -22 & 25 & $1-2$ \\
\hline
\end{tabular}


The linear max-min normalization method provides a different result since, as mentioned above, it transforms the negligible variations of $\mathrm{CO}$ and $\mathrm{HC}$ into significant values. According to this, this normalization technique leads to a solution with small $\mathrm{CO}$ and $\mathrm{HC}$ emissions. This alternative is a compromise between the four criteria analysed $\left(\mathrm{NO}_{\mathrm{x}}, \mathrm{SFC}, \mathrm{CO}\right.$, and $\left.\mathrm{HC}\right)$, providing more relevance to $\mathrm{CO}$ and $\mathrm{HC}$ than these really have. This alternative leads to a small contribution of pre-injection, with a 5\% quantity, due to the increment of SFC, CO, and $\mathrm{HC}$ with the pre-injection quantity. Besides, this solution does not lead to important pre-injection advancements also due to the SFC, $\mathrm{CO}$, and $\mathrm{HC}$ penalty. Since a $5 \%$ pre-injection quantity leads to excessive $\mathrm{NO}_{\mathrm{x}}$ emissions, this solution is not recommended due to the current legislation about $\mathrm{NO}_{\mathrm{x}}$ emissions.

On the other hand, the alternative obtained by the other normalization techniques provides significant $\mathrm{NO}_{\mathrm{x}}$ reductions with a small increment of SFC in comparison with the case without pre-injection. This solution proposes a high pre-injection percentage (i.e. 25\%) due to the effect on $\mathrm{NO}_{\mathrm{x}}$ reduction. As shown in Fig. 5, advancing the pre-injection starting instant also leads to important $\mathrm{NO}_{\mathrm{x}}$ reductions, resulting in $-22^{\circ}$ as pre-injection starting instant. Regarding preinjection duration, low values emerge since short injections provide important $\mathrm{NO}_{\mathrm{x}}$ reductions. $\mathrm{NO}_{\mathrm{x}}$ is mainly caused by the high temperatures that are reached during the combustion process [45]. In order to reduce $\mathrm{NO}_{\mathrm{x}}$ efficiently, the fuel must be rigorously injected at the optimum instant and thus under short injections.

\section{Conclusions}

The following conclusions may be drawn from the present work:

- Due to the important emissions of $\mathrm{NO}_{\mathrm{x}}$ produced in the marine field, the present work analyses a $\mathrm{NO}_{x}$ reduction policy in a commercial marine diesel engine. The measure proposed is a pre-injection system. Besides $\mathrm{NO}_{\mathrm{x}}$, the objective is to maintain SFC and emissions of $\mathrm{CO}$ and $\mathrm{HC}$ as low as possible. It is worth mentioning that PM emissions should also be included in this model. These were not included due to the difficulties to accurately predict these emissions through CFD.

- A total of 125 alternatives with different values of the pre-injection starting instant, quantity and duration were analyzed.

- Since the pre-injection starting instant, quantity and duration are conflicting criteria, a MCDM methodology was employed to determine the most suitable pre-injection configuration.

- An important step in MCDM is the normalization process. Many normalization methods can be found in the literature, and the five most employed ones were compared in the present work: linear max normalization, linear max-min normalization, linear sum normalization, vector normalization and logarithmic normalization.

- 3 MCDM approaches were compared: WSM, WPM, and TOPSIS.

- It was found that linear max, linear sum, vector, and logarithmic normalization methods provided practically the same result as most appropriate pre-injection pattern: $-22^{\circ} \mathrm{CA}$ ATDC pre-injection starting instant, $25 \%$ pre-injection quantity, and $1^{\circ}$ (WSM and WPM) or $2^{\circ}$ (TOPSIS) pre-injection duration due to the important $\mathrm{NO}_{\mathrm{x}}$ reductions with a low SFC penalty. Nevertheless, the linear max-min normalization technique provided a very different result: $-18^{\circ} \mathrm{CA}$ ATDC pre-injection starting instant, $5 \%$ pre-injection quantity, and $2^{\circ}$ preinjection duration. The reason of the discrepancy between the max-min normalization technique and the other normalization techniques lies in the range of the normalized values. The variation of $\mathrm{CO}$ and $\mathrm{HC}$ emissions in the 125 cases is practically irrelevant, but the linear max-min normalization technique increments the importance of these pollutants since it 
converts its values into the range [0 1]. On the other hand, the other normalization methods maintain the irrelevance of the variations of $\mathrm{CO}$ and $\mathrm{HC}$ and thus lead to another optimal configuration.

- Among the limiting aspects of MCDM methods, it is worth mentioning that, even if they provide a formal tool for decision making problems, subjectivity is not removed, due to the procedure to stablish the weights. In fact, different MCDM methods and different normalization procedures lead to different results, which means that there is no universal method suitable for all problems.

\section{Nomenclature}

$\begin{array}{ll}A I & \text { Adequacy index } \\ \alpha & \text { Requirement } \\ \beta & \text { Sub-requirement } \\ C & \text { Relative closeness to the ideal solution } \\ D & \text { Pre-injection duration } \\ D^{+} & \text {Euclidean distance from the positive ideal solution } \\ D^{-} & \text {Euclidean distance from the negative ideal solution } \\ D M & \text { Decision matrix } \\ i & \text { Alternative } \\ j & \text { Criterion } \\ m & \text { Number of alternatives } \\ n & \text { Number of criteria } \\ N D M & \text { Normalized decision matrix } \\ Q & \text { Pre-injection quantity } \\ R & \text { Weighted normalized data } \\ S & \text { Pre-injection starting instant } \\ S^{+} & \text {Positive ideal solution } \\ S^{-} & \text {Negative ideal solution } \\ V & \text { Normalized data } \\ w & \text { Weight } \\ X & \text { Data }\end{array}$

\section{Abbreviations}

$\begin{array}{ll}\text { ATDC } & \text { After Top Dead Center } \\ \text { BDC } & \text { Bottom Dead Center } \\ \mathrm{CA} & \text { Crank angle } \\ \mathrm{CFD} & \text { Computational Fluid Dynamics } \\ \mathrm{CO} & \text { Carbon monoxide } \\ \mathrm{CO}_{2} & \text { Carbon dioxide } \\ \mathrm{HC} & \text { Hydrocarbons } \\ \mathrm{IMO} & \text { International Maritime Organization } \\ \text { MADM } & \text { Multi-Attributes Decision Making } \\ \text { MEW } & \text { Multiplicative Exponential Weighting }\end{array}$




$\begin{array}{ll}\text { MCDA } & \text { Multiple-Criteria Decision Analysis } \\ \text { MCDM } & \text { Multiple-Criteria Decision Making } \\ \text { MDDM } & \text { Multiple-Dimensions Decision Making } \\ \text { MODM } & \text { Multiple-Objective Decision Making } \\ \text { NO }_{x} & \text { Nitrogen oxides } \\ \text { PM } & \text { Particulate matter } \\ \text { SFC } & \text { Specific Fuel Consumption } \\ \text { SO }_{x} & \text { Sulphur oxides } \\ \text { TDC }_{\text {TOPSIS }} & \text { Top Dead Center } \\ \text { WSM } & \text { Technique for Order Preference by Similarity to Ideal Solution } \\ \text { WPM } & \text { Weighted Sum Method }\end{array}$

\section{Acknowledgements}

The authors would like to express their gratitude to Norplan Engineering S.L. and recommend the courses "CFD with OpenFOAM" and "C ++ applied to OpenFOAM" available at www.technicalcourses.net.

\section{REFERENCES}

[1] Sinay, J.; Puskar, M.; Kopas, M. Reduction of the $\mathrm{NO}_{\mathrm{x}}$ emissions in vehicle diesel engine in order to fulfill future rules concerning emissions released into air. Science of the Total Environment, vol. 624, pp. 14211428, 2018, https://doi.org/10.1016/j.scitotenv.2017.12.266

[2] Sencic, T.; Mrzljak, B.; Bonefacic, I. 2D CFD simulation of water injection strategies in a large marine engine. Journal of Marine Science and Engineering, vol. 7, 296, 2019, https://doi.org/10.3390/jmse7090296

[3] Shen, H.; Zhang, J.; Yang, B.; Jia, B. Development of a marine two-stroke diesel engine MVEM with incylinder pressure trace predictive capability and a novel compressor model. Journal of Marine Science and Engineering, vol. 8, 204, 2020, https://doi.org/10.3390/jmse8030204

[4] Perez, J. R.; Reusser, C.A. Optimization of the emissions profile of a marine propulsion system using a shaft generator with optimum tracking-based control scheme. Journal of Marine Science and Engineering, vol. 8, 221, 2020, https://doi.org/10.3390/jmse8030221

[5] Sui, P.; Stapersma, D.; Visser, K.; Ding, Y. Fuel consumption and emissions of ocean-going cargo ship with hybrid propulsion and different fuels over voyage. Journal of Marine Science and Engineering, vol. 8, 588, 2020, https://doi.org/10.3390/jmse8080588

[6] Sead, C.; Dragan, I. Application of diagnosis as a basis of condition based maintenance of the marine propulsion diesel engine. Brodogradnja, vol. 71, pp. 119-134, 2020, https://doi.org/10.21278/brod71307

[7] Seddiek, I. S.; Elgohary, M. M.; Ammar, N. R. The hydrogen-fuelled internal combustion engines for marine applications with a case study. Brodogradnja, vol. 66, pp. 23-38, 2015.

[8] Elgohary, M. M.; Ammar, N. R.; Seddiek, I. S. Steam and sofc based reforming options of pem fuel cells for marine applications. Brodogradnja, vol. 66, pp. 61-76, 2015.

[9] Winnes, H.; Fridell, E.; Moldanová, J. Effects of marine exhaust gas scrubbers on gas and particle emissions. Journal of Marine Science and Engineering, vol. 8, 299, 2020, https://doi.org/10.3390/jmse8040299

[10] Puskar, M.; Kopas, M.; Sabadka, D.; Kliment, M.; Soltesova, M. Reduction of the gaseous emissions in the marine diesel engine using biodiesel mixtures. Journal of Marine Science and Engineering, vol. 8, 330, 2020, https://doi.org/10.3390/jmse8050330

[11] Pistek, V.; Kucera, P.; Fomin, O.; Lovska, A. Effective mistuning identification method of integrated bladed discs of marine engine turbochargers. Journal of Marine Science and Engineering, vol. 8, 379, 2020, https://doi.org/10.3390/jmse8050379 
[12] Witkowski, K. Research of the effectiveness of selected methods of reducing toxic exhaust emissions of marine diesel engines. Journal of Marine Science and Engineering, vol. 8, 452, 2020, https://doi.org/10.3390/jmse8060452

[13] Zalacko, R.; Zoldy, M.; Simongati, G. Comparative study of two simple marine engine BSFC estimation methods. Brodogradnja, vol. 71, pp. 13-25, 2020, https://doi.org/10.21278/brod71302

[14] Varbanets, R.; Fomin, O.; Pistek, V.; Klymenko, V.; Minchev, D.; Khrulev, A.; Zalozh, V.; Kucera, P. Acoustic method for estimation of marine low-speed engine turbocharger parameters. Journal of Marine Science and Engineering, vol. 9, 321, 2021, https://doi.org/10.3390/jmse9030321

[15] Monieta, J.; Sendecki, A. Database and knowledge about essential manufacturers of marine self-ignition engines. Journal of Marine Science and Engineering, vol. 8, 239, 2020. https://doi.org/10.3390/jmse8040239

[16] Monieta, J. Diagnosing marine piston engines driving generators at different operational loads. Journal of Marine Science and Engineering, vol. 9, 132, 2021. https://doi.org/10.3390/jmse9020132

[17] Jahan, A.; Edwards, K. L. A state-of-the-art survey on the influence of normalization techniques in ranking: Improving the materials selection process in engineering design. Materials \& Design, vol. 65, pp. 335-342, 2015, https://doi.org/10.1016/j.matdes.2014.09.022

[18] Eftekhary, M.; Gholami, P.; Safari, S.; Shojaee, M. Ranking normalization methods for improving the accuracy of SVM algorithm by DEA method. Modern Applied Science, vol. 6, 2012, https://doi.org/10.5539/mas.v6n10p26

[19] Milani, A. S.; Shanian, A.; Madoliat, R.; Nemes, J. A. The effect of normalization norms in multiple attribute decision making models: a case study in gear material selection. Structural and Multidisciplinary Optimization, vol. 29, pp. 312-318, 2005, https://doi.org/10.1007/s00158-004-0473-1

[20] Chatterjee, P.; Chakraborty, S. Investigating the effect of normalization norms in flexible manufacturing system selection using Multi-Criteria Decision-Making methods. Journal of Engineering Science \& Technolgy Review, vol. 7, pp. 141-150, 2014, https://doi.org/10.25103/jestr.073.23

[21] Pavlicic, D. M. Normalisation affects the results of MADM methods. Yugoslav Journal of Operations Research, vol. 11, pp. 251-265, 2001.

[22] Chakraborty, S.; Yey, C. H. A simulation comparison of normalization procedures for TOPSIS. In 2009 International Conference on Computers \& Industrial Engineering, Jul. 2009, pp. 1815-1820, https://doi.org/10.1109/ICCIE.2009.5223811

[23] Acuña-Soto, C.; Liern, V.; Perez-Gladish, B. Normalization in TOPSIS-based approaches with data of different nature: application to the ranking of mathematical videos. Annals of Operational Research, vol. 296, pp. 541-569, 2021, https://doi.org/10.1007/s10479-018-2945-5

[24] Celen, A. Comparative analysis of normalization procedures in TOPSIS method: with an application to Turkish deposit banking market. Informatica, vol. 25, pp. 185-208, 2014, https://doi.org/10.15388/Informatica.2014.10

[25] Vafaei, N.; Ribeiro, R. A.; Camarinha-Matos, L. M. Normalization techniques for Multi-Criteria Decision Making: analytical hierarchy process case study. Doctoral Conference on Computing, Electrical and Industrial Systems, pp. 261-269, 2016. https://doi.org/10.1007/978-3-319-31165-4_26

[26] Vafaei, N.; Ribeiro, R. A.; Matos, L. M. C. Data normalisation techniques in decision making: case study with TOPSIS method. International Journal of Information and Decision Sciences, vol. 10, pp. 19, 2018, https://doi.org/10.1504/IJIDS.2018.090667

[27] Lamas, M. I.; Castro-Santos, L.; Rodriguez, C. G. Optimization of a multiple injection system in a marine diesel engine through a Multiple-Criteria Decision-Making approach. Journal of Marine Science and Engineering, vol. 8, pp. 946, 2020, https://doi.org/10.3390/jmse8110946

[28] Lamas, M. I.; Rodriguez, C. G.; Rebollido, J. Numerical model to study the valve overlap period in the Wärtsilä 6L 46 four-stroke marine engine. Polish Maritime Research, vol. 19, 2012, https://doi.org/10.2478/v10012-012-0004-8

[29] Lamas, M. I.; Rodriguez, C. G.; Rodriguez, J. D.; Telmo, J. Internal modifications to reduce pollutant emissions from marine engines. A numerical approach. International Journal of Naval Architecture and Ocean Engineering, vol. 5, 2013, https://doi.org/10.2478/IJNAOE-2013-0148

[30] Lamas, M. I.; Rodriguez, C. G. Numerical model to study the combustion process and emissions in the Wärtsilä 6L 46 four-stroke marine engine. Polish Maritime Research, vol. 20, pp. 61-66, 2013, https://doi.org/10.2478/pomr-2013-0017 
[31] Lamas, M. I.; Rodriguez, C. G.; Telmo, J.; Rodriguez, J. D. Numerical analysis of emissions from marine engines using alternative fuels. Polish Maritime Research, vol. 22, pp. 48-52, 2015, https://doi.org/10.1515/pomr-2015-0070

[32] Lamas, M. I.; Rodriguez, J. D.; Castro-Santos, L.; Carral, L. M. Effect of multiple injection strategies on emissions and performance in the Wärtsilä 6L 46 marine engine. A numerical approach. Journal of Cleaner Production, vol. 206, pp. 1-10, 2019, https://doi.org/10.1016/j.jclepro.2018.09.165

[33] Lamas Galdo, M. I.; Castro-Santos, L.; Rodriguez Vidal, C. G. Numerical analysis of $\mathrm{NO}_{\mathrm{x}}$ reduction using ammonia injection and comparison with water injection. Journal of Marine Science and Engineering, vol. 8, 109, 2020, https://doi.org/10.3390/jmse8020109

[34] Dukowicz, J. K. A particle-fluid numerical model for liquid sprays. Journal of Computational Physics, vol. 35, pp. 229-253, 1980, https://doi.org/10.1016/0021-9991(80)90087-X

[35] Ricart, L. M.; Xin, J.; Bower, G. R.; Reitz, R. D. In-cylinder measurement and modeling of liquid fuel spray penetration in a heavy-duty diesel engine. 1997, https://doi.org/10.4271/971591

[36] Ra, Y.; Reitz, R. D. A reduced chemical kinetic model for IC engine combustion simulations with primary reference fuels. Combustion and Flame, vol. 155, pp. 713-738, 2008, https://doi.org/10.1016/j.combustflame.2008.05.002

[37] Yang, G, H.; Krishnan, S. R.; Srinivasan, K. K.; Midkiff, K. C. Modeling of $\mathrm{NO}_{\mathrm{x}}$ emissions using a superextended Zeldovich mechanism. 2003. https://doi.org/10.1115/ICEF2003-0713

[38] Miller, J. A.; Glarborg, P. Modeling the formation of N2O and NO2 in the thermal DeNOx process. Inernational Journal of Chemical Kinetics, vol. 26, pp. 421-436, 1996. https://doi.org/10.1007/978-3-64280299-7_25

[39] Loffler, G.; Sieber, R.; Harasek, M.; Hofbauer, H.; Hauss, R.; Landaul, J. NOx,formation in natural gas combustion-a new simplified reaction scheme for CFD calculations. Fuel, vol. 85, 513-523, 2006, doi: 10.1016/j.fuel.2005.07.012. https://doi.org/10.1016/j.fuel.2005.07.012

[40] Hernandez, J.J.; Lapuerta, M.; Perez-Collado, J. A combustion kinetic model for estimating diesel engine NOx emissions. Combustion Theory and Modelling, vol. 10, 639-657, 2006, https://doi.org/10.1080/13647830600632758

[41] Vinogradova, I.; Podvezko, V.; Zavadskas, E. The recalculation of the weights of criteria in MCDM methods using the bayes approach. Symmetry (Basel), vol. 10, 205, 2018, https://doi.org/10.3390/sym10060205

[42] Churchman, C. W.; Ackoff, R. L. (1954). An approximate measure of value. Journal of Operations Research Society of America, vol. 2, pp. 172-187, 1954. https://doi.org/10.1287/opre.2.2.172

[43] Bridgman, P. W. Dimensional Analysis. New Haven: Yale University Press. 1922.

[44] Hwang C. L., Yoon K. Methods for Multiple Attribute Decision Making. In: Multiple Attribute Decision Making. Lecture Notes in Economics and Mathematical Systems, vol 186. 1981. Springer, Berlin, Heidelberg, https://doi.org/10.1007/978-3-642-48318-9 3

[45] Lamas-Galdo, M. I.; Castro-Santos, L.; Rodriguez-Vidal, C. G. Selection of an appropriate pre-injection pattern in a marine diesel engine through a multiple-criteria decision making approach. Applied Sciences, vol. 10, 2482, 2020, https://doi.org/10.3390/app10072482

$\begin{array}{lll}\text { Submitted: } & \text { 05.08.2021. } & \text { Carlos Gervasio Rodríguez } \\ & \text { University of Coruña, Spain } \\ \text { Accepted: } & \text { 12.10.2021. } & \text { María Isabel Lamas, isabel.lamas.galdo@udc.es } \\ & \text { University of Coruña, Spain } \\ & \text { Juan de Dios Rodríguez } \\ & \text { University of Coruña, Spain } \\ & \text { Claudio Caccia } \\ & \text { Politecnico di Milano, Italy }\end{array}$

